\title{
Cause-Related Marketing and Its Impact on Buying Intention
}

\author{
Vibhas Amawate, Madhurima Deb, Mohit Manchanda \\ Indian Institute of Management Kashipur, Kashipur, India \\ Email: vibhas.efpm2014@iimkashipur.ac.in, madhurimadeb@yahoo.com, mohit.efpm2016@iimkashipur.ac.in
}

How to cite this paper: Amawate, V., Deb, M. and Manchanda, M. (2019) Cause-Related Marketing and Its Impact on Buying Intention. Theoretical Economics Letters, 9, 2139-2151.

https://doi.org/10.4236/tel.2019.96135

Received: January 29, 2019

Accepted: August 27, 2019

Published: August 30, 2019

Copyright $\odot 2019$ by author(s) and Scientific Research Publishing Inc. This work is licensed under the Creative Commons Attribution International License (CC BY 4.0).

http://creativecommons.org/licenses/by/4.0/ (c) (i) Open Access

\begin{abstract}
Objective: The primary objective of the present study is to understand the impact of Cause-Related Marketing (CRM) on customer's buying intention. Methodology: In the present study quantitative technique was used for collecting data. Data were analyzed using SPSS. Findings: The result shows the relationship between Suitability of the Campaign (SoC) to Evaluation of Campaign (EC) was found negative and insignificant. The relationship between EC to Controllability of Efforts (CoE) was also found negative but significant. The relationship between EC to Perceived Motivational Attribution (PMA) and between PMA to Behavioural Outcome (BOI) was found positive and significant. Originality and Contribution: The present sector. The study will help academicians understand factors impacting CRM and outcome study is expected to contribute to the literature on Cause Related Marketing in the context of automobile of CRM. Policy makers will also be benefitted by such knowledge. There are very few works done in the context of India and hence the present work is expected to contribute to the existing literature on CRM.
\end{abstract}

\section{Keywords}

CRM, Motivation, Buying Intention

\section{Introduction}

Vardarajan and Menon [1] were the first to coin the term Cause-Related Marketing (CRM). Their work is also credited with linking how Corporate Social Responsibility (CSR) can help companies generate goodwill for themselves and strengthen their brand values. As Varadarajan and Menon [1] define, cause-related marketing (CRM) is the marketing activities characterizing donations offered by corporate organizations to a charity cause. It became a frequently used market- 
ing approach in the early 1990s. Since then, CRM has gained ever-growing popularity among brand marketers, who believe this approach helps to enhance both brand attitude and purchase intention [2] [3].

The CSR concept was developed from two sources at different times, one was CSR as business ethics and the other as part of sustainable development programs, but converged as a business norm after the millennium [4]. One of the definitions of CSR was given by Bowen [5] where he defined CSR as the organizations' social commitment to go after the corporate policies to make decisions which are useful to the interest or values of the community. Another definition provided by Davis and Blomstrom [6] emphasizes the balance that the organization should try to achieve via CSR, balance between the welfare of the community and the business objective of the organization. Davis and Blomstrom defined the CSR as a term that indicates to the organization's obligation to improve the interest of the community as well as to achieve the objectives of the organization. Furthermore, it had been found that from the perspective of customers, the firm's CSR strategies can improve company image in the mind of customers thus improving the customer's loyalty and patronage intention [7]. The CSR activities undertaken by companies were found to create more emotional attachment of the customers to the firm, increasing customer's satisfaction and improving the customer-company relationship [8].

CSR and CRM are closely linked to each other. CRM is defined by Adkins [9] as "activity which businesses and charities or causes form a partnership with each other to market an image, product or service for mutual benefit". Varadarajan and Menon [1] view cause-related marketing amongst CSR initiatives that "Do Better by Doing Good". In other words, they believe it not only enhances company revenue but in addition contributes to societal welfare. Their definition of CSR is, "The process of formulating and implementing marketing activities that are characterised by an offer from the firm to contribute a specified amount to a designated cause when customers engaging in revenue-providing exchanges that satisfy organisational and individual objectives" [10]. The paragraph below brings forth an example of CSR program practiced by one of the leading automobile company of India-MSIL (Maruti Suzuki India Limited).

CSR in India: Focused Example of MSIL, the Leader in Indian Automobile Sector

In the year 2013, CSR was made compulsory for companies in India. Ministry of Corporate Affairs (MCA) under Section 135 and Schedule VII of the Companies Act, 2013, had notified that it would be mandatory for companies to spend 2 percent of their three-year average annual net profit on Corporate Social Responsibility activities in each financial year, starting from FY15. It was mandatory for companies with at least 5 crore net profit or 1000 crore turnover or 500 crore net worth. Since then many companies were actively involved in it. However, there were companies in India that were contributing to CSR before the act was passed. One such company is Maruti Suzuki India Limited (MSIL). MSIL 
intention has been to focus on few CSR programmes rather than spread its scarce resources across multiple projects and make a marginal impact. MSIL through its CSR programmes like community development and skill development had participated in the Indian Government's famous "Swachh Bharat Abhiyan" (Clean India Campaign) and Skill India projects. MSIL has separate teams with the appropriate expertise and experience to implement various CSR programmes of the company and their activities are all coordinated at the corporate level. People involved in the CSR projects consisted of professionals with qualifications in engineering, business management, social work and mass communications, etc. MSIL also partners with different not-for-profit organizations to discharge its CSR projects. Each year the performance of the CSR programme is reviewed. MSIL's CSR work was focused around three areas namely 1) community development, 2) skill development and 3) road safety. It had also included healthcare as a focus area under community development-oriented CSR activities.

Maruti Suzuki's driving training schools which were also a part of the company's CSR programme under the area of road safety had been active in training people on driving safely. As of 2017, the company's driving school had trained 2.95 lakh people (34\% more than last year). It had added 40 new driving schools during 2016-2017, taking the number to 400 across 190 cities. MSIL has 6 Institutes of Driving Training \& Research to educate drivers on road safety. The company also had plans to invest in new and innovative technologies particularly in the area of road safety for traffic management and control as part of its corporate social responsibility (CSR) initiatives. The company also had planned during FY 2017-2018 to invest upto 1.40 billion in CSR activities. The company had launched road safety mission during 2017 with the objective of training almost 500,000 people in three years. The proposal was to be executed through two channels-1) Institute of Driving Training and Research (IDTR) and 2) the Maruti Driving Schools spread across the country. Of the 500,000 people to be trained, at least 100,000 would be from underprivileged section of society, who intends to take driving as their profession for earning livelihood.

The initiative, "Maruti Traffic Heroes of India" was the combined endeavor of Maruti Suzuki, Radio Mirchi (Indian Music Radio Station) and Traffic Police Department of Delhi (capital state of India), wherein Radio was the medium of communication. Radio as a medium was starting to gain popularity as a travel companion. The popularity of the medium as well as its live connects with the populace meant that it could be a medium to inform and educate consumers on any topic which require immediate attention. Radio Nation was a leading radio channel which was controlled by the Government of India and had presence in 9 major cities of India. The radio channel was one of only channels before the de-regulation of the radio industry. So MSIL in association with Radio launched the CRM initiative called as "Maruti Suzuki Traffic Beats". At the start of this program, Maruti Suzuki invested by creating a panel of travelers who reported 
on the traffic situation on the route which they were travelling, this was for the first time that people were getting to know of the traffic situation. The initiative by MSIL which started during 2000 as "Maruti Suzuki Traffic Beat" was meant to reduce the road accident. Despite being one of the fastest growing automobile markets in the world, safety on Indian roads is far from global standards. As per data available, Indian roads account for the highest fatalities in the world. In the year 2015, more than 0.146 million people lost their lives in road accidents and 500,279 people were injured. MSIL, one of the leading automobile manufacturers in association with Radio and Traffic Police wanted to bring the fatality rate to zero in India. Road safety measure and "Maruti Traffic Heroes of India" was a CSR (Corporate Social Responsibility) initiative of MSIL.

As part of the activity, a convoy of branded cars were flagged off daily to visit 10 traffic signals and cover important market places, residential colonies, schools and colleges on the way starting from 12 January 2017 it was meant to run for a week. At every traffic signal, the Radio Mirchi personnel thanked the city's traffic police personnel who were responsible for road safety by monitoring the travelers at each traffic point. The convoy in order to recognize the real people also gave out prizes to people who were found adhering to traffic rules on random basis. The people were also asked to take pledge to follow road safety by signing a pledge card. The program was gradually launched at other cities of India too like Bangalore, Chennai, Kolkata, Lucknow, Chandigarh, Indore, Ahmedabad, Kochi, Pune, Mumbai and Hyderabad apart from beginning it at Delhi NCR Region.

Like MSIL many other automobile companies in India were involved in CSR programs. The programs might be different but are part of legal compliance. The motivation of the present study was to find empirical evidence for the impact of marketing of CSR activities or in other words impact of Cause-Related Marketing on customer's motivation to patronize the brand. The study is focused on Indian automobile sector as can be seen from the above that Indian automobile sector is into CRM in a big way.

The objective of the present study is to understand if these programs apart from meeting legal compliance can become a useful source for companies to leverage their reputation in the minds of customers and enable them to develop improved buying intention? The literature suggests that CSR helps companies to develop goodwill for themselves and it can be leveraged to improve customer's buying intentions. The present study intends to validate the above in the context of Indian automobile sector.

\section{Conceptual Model}

Varadarajan and Menon [1] defined, cause-related marketing (CRM) is the marketing activities characterizing donations offered by corporate organizations or product brands to a charity cause. It became a frequently used marketing approach in the early 1990s. Since then, CRM had gained ever-growing popularity 
among brand marketers, who believed this approach helps to enhance both brand attitude and purchase intention [11]. The conceptual model below discusses in detail the process of how CRM can lead to positive purchase intention (Figure 1).

The CRM campaign of a firm is judged by customer based on factors like Suitability of the campaign. Suitability of CRM campaign (SOC) is defined as customer's belief that the CRM campaign fits the business domain of the company funding the CRM program. The contrast effect theory suggests that a CRM program may be evaluated by consumers differently for one company as opposed to another company [12]. The suitability of CRM campaign depends on the consumers' pre-existing knowledge about the domain of the company involved in the CRM campaign [12]. If the customer's perceive the domain of the company fits well with the cause that the company is supporting then it leads to positive evaluation of the CRM campaign and vice versa [13]. If the cause supported in the campaign does not sync well with the domain of the company then leads to

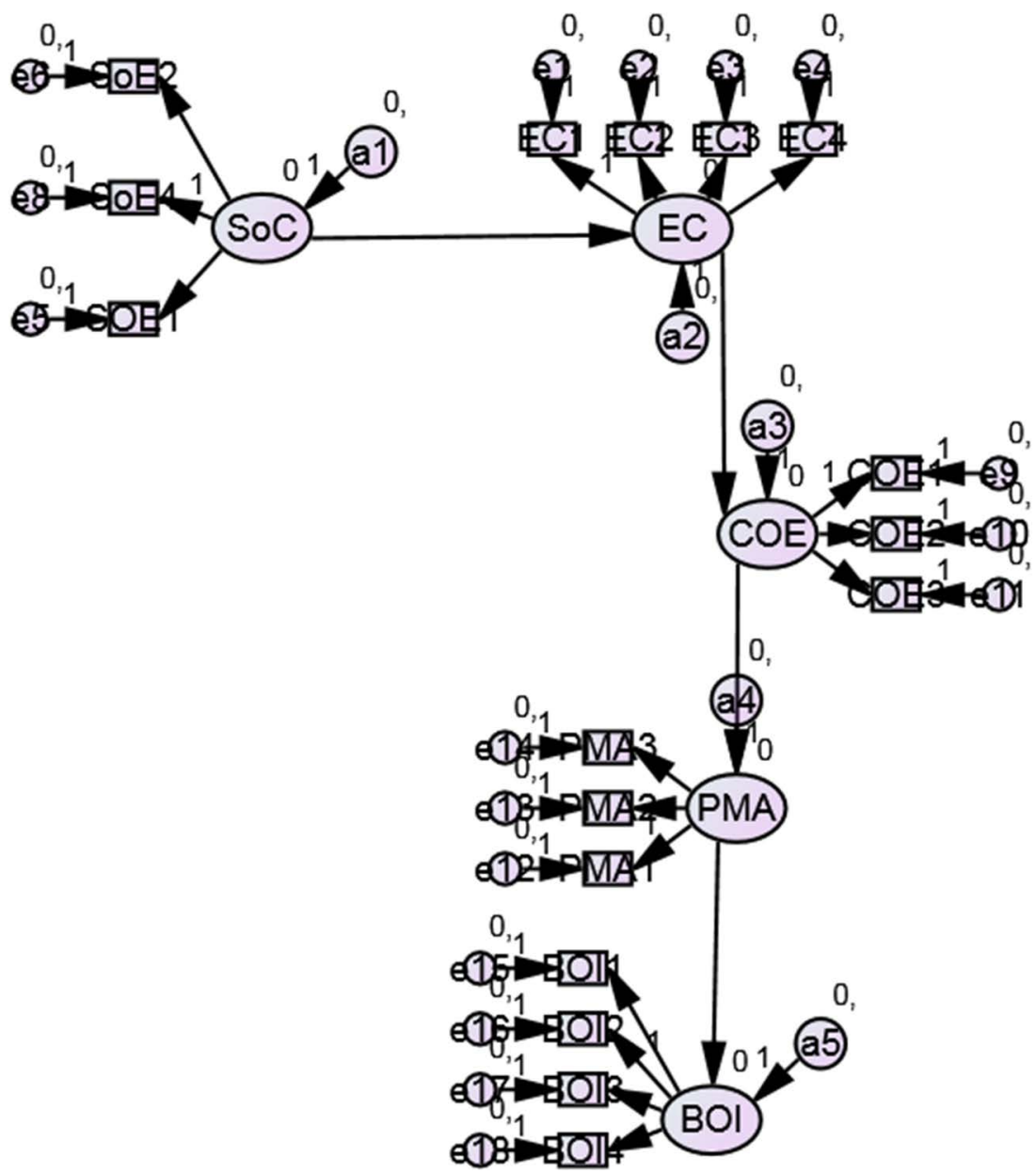

(a1-a5 \& e1-e18 are all errors or unexplained variances; factors are captured in the oval and measured variables are captured in the rectangle: BOI is the Buying Intention; PMA is the Perceived Motivational Attribution; $\mathrm{COE}$ is the Controllability of the Campaign; EC is the Evaluation of the Campaign; SOC is the Suitability of the Campaign).

Figure 1. SEM model. 
negative evaluation of the CRM campaign [12]. Hence from the above it can be hypothesized that:

$H 1$ : Suitability of the campaign (SOC) is positively related to evaluation of the campaign (EC).

As per attribution theory consumers attribute causes to the consequences of the event. One of the dimensions of the whole casual process attribution is the perceived controllability of CRM campaign. It is the perception that the company funding the CRM campaign is capable of addressing the cause and bringing positive change [12] [14] [15] [16]. If the campaign is evaluated negatively then the customer perceive that the cause supported in the CRM campaign is beyond the capability of the firm involved in the CRM campaign and vice versa [11] [12] [13]. If the campaign is evaluated positively then it leads to positive perception about the capability of the firm involved in it. We hypothesize that when a consumer evaluates a CRM campaign he is looking at ability of the sponsoring companies to address the cause and bring about a positive change in the society.

$H 2$ : There is positive relationship between evaluation of the campaign and the controllability of the campaign.

Positive Motivational Attribution (PMA) process is central to determining the success or failure of CRM [11] [12] [13]. Such process determines consumers' perceptions of the parent brand's CRM engagement motives [17] [18] [19]. Positive attribution emerges in cases of altruistic perceptions (presence of persuasive components in the CRM campaign that further prove the authenticity of the campaign, that the campaign is for supporting a true cause and addressing the same rather than focusing on the self-interest of the company) about company's motives, whereas negative attribution emerges in cases of egoistic perceptions (that the CRM campaign is for the self-benefit of the company rather than addressing any social cause) [11] [12] [13]. The consumer's belief that the company funding the CRM campaign is able/not able to address the cause is driven by the consumers perception's about the motive behind initiating the CRM campaign. If the consumer believes the motives to be focused on creating societal good rather serving the business goals of the company funding the CRM campaign, they are more likely to have a Positive Motivational Attribution (PMA). Thus we hypothesize that consumer perception that the controllability of the campaign is high leads to PMA.

H3: Controllability of the campaign is positively related to PMA.

Positive Motivational Attribution would induce a moral pleasure for participation and a moral displeasure for non participation. Moral Pleasure induced by PMA would bring forth favorable attitudinal and behavioral propensities towards the brand [10] [11] [14]. Thus we hypothesize that PMA is positively related to buying intention.

H4: PMA is positively related to buying intention.

\section{Methodology}

Data were collected from a sample of 253 customers who were selected based on 
snowballing technique (in snowballing technique the next participant(s) are selected based on referrals obtained from the previous participants). The screening criteria were, if they own any brand of passenger vehicle and if they are aware about the brand's CSR programs which they own. To develop measurement for constructs in the proposed conceptual model, the researcher took into account the key concepts of the moral judgment theory, attribution theory and confirmation bias theory mentioned in the previous sections as proposed by [11] [13] Respondents were aged between 28 and 35, with college educational backgrounds and annual income level (ranging from INR 35,000 to INR 50,000). Besides, the participants were evenly distributed in gender. Respondents were aware of the objective and process of the survey, they were willing to cooperate.

The process of data analysis begins with reducing the number of variables to a reduced set for better interpretation using Factor Analysis. Table 1 shows the details of the Rotated Component Matrix. It can be observed that 18 observed variables were reduced to 5 factors. Confirmatory Factor Analysis (CFA) was used to reducing a number of variables into a smaller number of factors which can improve the interpretation. Variables which loaded more than 0.50 on respective factors were grouped under the factor as underlying dimensions of that factor. Since the variables under each factor are correlated with each other hence are grouped together. Deducing interpretation with 5 factors is easier then 18 variables. Table 1 also shows the labels for each of the Factors. Table 2 shows the cleanliness of the measurement items or questionnaire items.

Under the cleanliness of measurement items the following things are checked:

- Unidimentionality of the variables: indicated by the factor loadings. Each variable should load more than 0.30 on each factor. Higher the loading better the unidimentionality. Unidimentionality means variable is measuring only that factor and not cross-loaded on other factors. If it's also loaded on other factors it disturbs the interpretation.

- Reliability: it means the reliable and is testing what its suppose to test. Its checked using composite reliability and composite variance. The formulae for composite reliability is:

- Composite Reliability = Square of the sum of the loadings for a particular factor/(Square of the sum of the loadings for a particular factor + Sum of the errors).

- Composite Variance = Sum of the $R^{2} /\left(\right.$ Sum of the $R^{2}+$ Sum of the errors).

- $R$ square is loading square and Error is $1-R$ square.

- $R$ is the loading and $R$ square is the explained variance and $1-R$ square is the unexplained variance or the error.

Results of Confirmatory Factor Analysis (CFA) revealed that the appropriate items loaded at least 0.55 on their respective hypothesized Factors. Reliability was indicated by composite reliability measures all exceeding 0.70 and the average percentage of variance extracted for each construct was nearly greater than 0.50 [15]. In summary, the measurement model is clean, with evidence for unidimensionality, convergent validity, reliability. 
Table 1. Rotated component matrix.

\begin{tabular}{|c|c|c|c|c|c|}
\hline \multicolumn{6}{|c|}{ Rotated Component Matrix ${ }^{\mathrm{a}}$} \\
\hline & \multicolumn{5}{|c|}{ Component } \\
\hline & 1 & 2 & 3 & 4 & 5 \\
\hline $\mathrm{EC} 1$ & & & & 0.723 & \\
\hline $\mathrm{EC} 2$ & & & & 0.798 & \\
\hline EC3 & & & & 0.817 & \\
\hline $\mathrm{EC} 4$ & & & & 0.861 & \\
\hline SOE1 & & & & & 0.903 \\
\hline SOE2 & & & & & 0.931 \\
\hline SOE4 & & & & & 0.900 \\
\hline CoE1 & 0.920 & & & & \\
\hline CoE2 & 0.919 & & & & \\
\hline CoE3 & 0.927 & & & & \\
\hline PMA1 & & & 0.881 & & \\
\hline PMA2 & & & 0.895 & & \\
\hline PMA3 & & & 0.892 & & \\
\hline BOI1 & & 0.884 & & & \\
\hline BOI2 & & 0.928 & & & \\
\hline BOI3 & & 0.935 & & & \\
\hline BOI4 & & 0.057 & & & \\
\hline
\end{tabular}

Extraction method: principal component analysis. Rotation method: varimax with Kaiser normalization (details of the coding provided under Table 4 of the case exhibit).

Structural Equation Modeling (SEM), a procedure for estimating series of relationships between independent and dependent factors which are represented by a conceptual model. Once the analysis is run the table output can be viewed from the view output tab at the left-hand side tabs. Results of the SEM can be viewed in Table 3 \& Table 4. The results (in Table 3 and Table 4) show the relationship between Suitability of the Campaign (SoC) and Evaluation of Campaign (EC) (H1) was found negative and insignificant. The relationship between EC and Controllability of Efforts ( $\mathrm{CoE})(\mathrm{H} 2)$ was also found negative but significant. The relationship between EC and Perceived Motivational Attribution (PMA) (H3) and between PMA and Behavioural Outcome (BOI) (H4) was found positive and significant (Figure 2).

\section{Conclusions}

In the present case, the relationship between Suitability of Campaign to Evaluation of Campaign was found negative and insignificant. The relationship between Evaluation of Campaign to the Controllability of the Effort was also found negative and significant. In the present case, it was found that customers perce- 
ive that Suitability of the Campaign is negatively related to the Evaluation of the Campaign. One probable reason could be a good fit between the CRM program and the company indicates that the company is involved in the CRM program for building its image, for self development rather than doing something for the

Table 2. Confirmatory factor analysis (CFA).

\begin{tabular}{cccccc}
\hline Variables & $\begin{array}{c}\text { Factor } \\
\text { Loadings }\end{array}$ & R square & Error & $\begin{array}{c}\text { Composite } \\
\text { Reliability }\end{array}$ & $\begin{array}{c}\text { Composite } \\
\text { Variance }\end{array}$ \\
\hline EC1 & 0.723 & 0.523 & 0.477 & & \\
EC2 & 0.798 & 0.636 & 0.364 & 0.877 & 0.642 \\
EC3 & 0.817 & 0.667 & 0.333 & & \\
EC4 & 0.861 & 0.742 & 0.258 & & \\
SoE1 & 0.903 & 0.815 & 0.185 & & \\
SoE2 & 0.931 & 0.868 & 0.132 & 0.936 & \\
SoE4 & 0.900 & 0.809 & 0.191 & & \\
COE1 & 0.920 & 0.847 & 0.153 & & \\
COE2 & 0.919 & 0.845 & 0.155 & 0.945 & \\
COE3 & 0.927 & 0.859 & 0.141 & & \\
PMA1 & 0.881 & 0.777 & 0.223 & & \\
PMA2 & 0.895 & 0.801 & 0.199 & 0.930 \\
PMA3 & 0.892 & 0.796 & 0.204 & & \\
BOI1 & 0.884 & 0.781 & 0.219 & & \\
BOI2 & 0.928 & 0.861 & 0.139 & & \\
BOI3 & 0.935 & 0.873 & 0.127 & & \\
BOI4 & 0.800 & 0.640 & 0.360 & & \\
\hline
\end{tabular}

Table 3. Unstandardised regression weights from SEM.

\begin{tabular}{ccccccc}
\hline & Structural Path & & Estimate & S.E. & C.R. & P \\
\hline EC & $<---$ & SoC & -0.071 & 0.055 & -1.288 & 0.198 \\
COE & $<---$ & EC & -0.663 & 0.237 & -2.792 & 0.005 \\
PMA & $<---$ & COE & 0.352 & 0.034 & 10.406 & $* * *$ \\
BOI & $<---$ & PMA & 0.418 & 0.063 & 6.684 & $* * *$ \\
\hline
\end{tabular}

(*** means $99 \%$ significance and 0.005 means $95 \%$ significance).

Table 4. Standardized regression weights from SEM.

\begin{tabular}{cccc}
\hline & Structural Path & & Estimate \\
\hline EC & $<---$ & SoC & -0.093 \\
COE & $<---$ & EC & -0.196 \\
PMA & $<---$ & COE & 0.577 \\
BOI & $<---$ & PMA & 0.406 \\
\hline
\end{tabular}




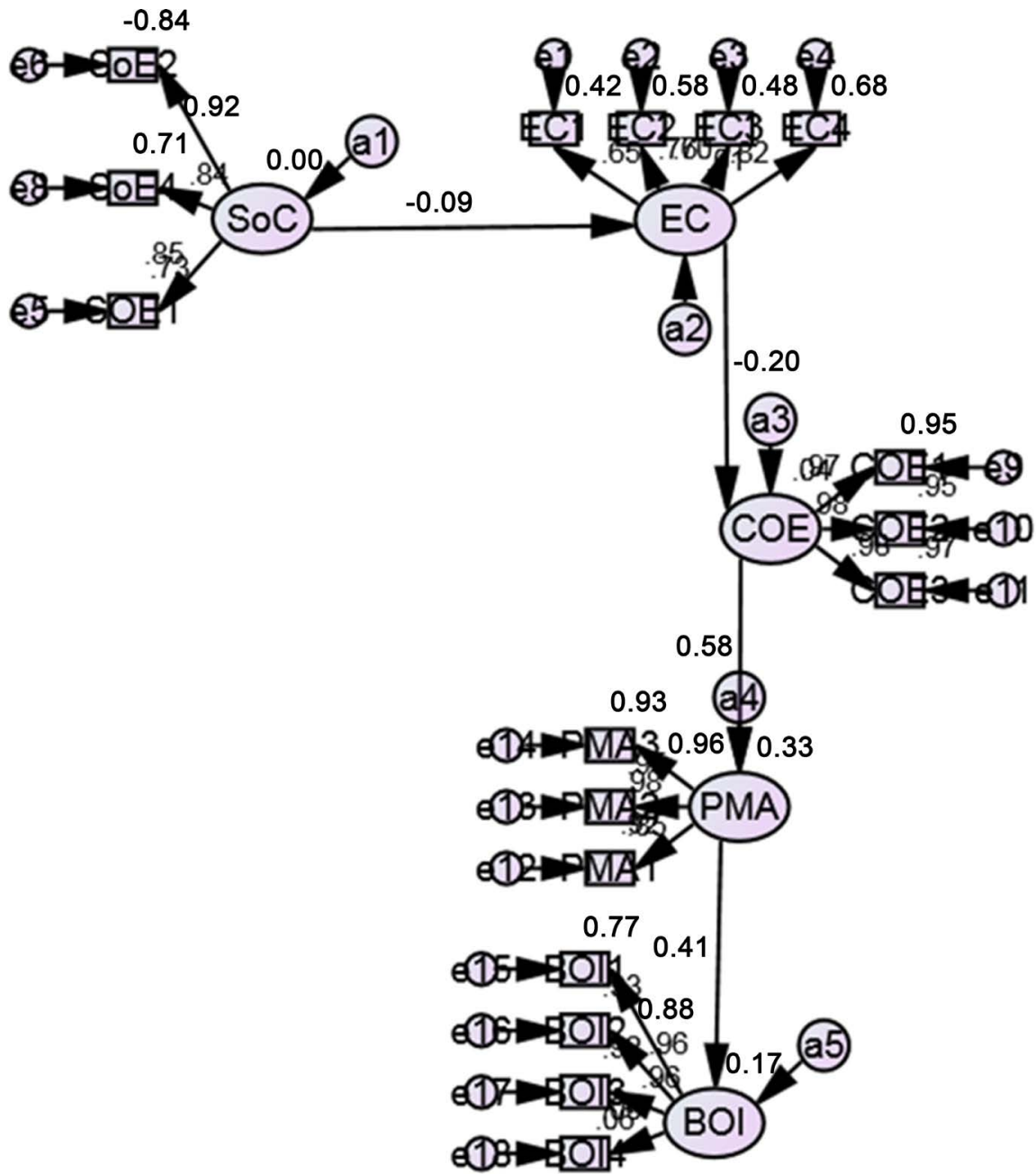

(All the values in the figures as imported from AMOS are separately and clearly presented under Table 3 and Table 4 which show these values with clarity).

Figure 2. Standardized regression weights from sem in the path diagram.

welfare of the society. The fit might indicate that a company is making conscious efforts to highlight its domain and not do something genuinely for the society. Hence the campaign was not evaluated positively. Low fit may indicate positive Evaluation of Campaign. Also, the relationship between the Evaluation of the Campaign to Controllability of Efforts was found negative. Though the respondent's do not perceive that the Campaign is compelling, trustworthy, convincing and relevant still they believed that company will be able to control it and can address the cause of CRM. One probable reason could be that the respondents believe that company can bring the road accidents to zero as they have positive faith and goodwill about the company, which is a giant and number one automobile company in India.

The relationship between Controllability of Efforts and Positive Motivation Attribution was found positive and significant. This is different from the previous two hypotheses as discussed above. Respondents perceive that the CRM program by the company would generate positive outcome and hence they are 
positively motivated towards the company (donor brand). Finally the relationship between Positive Motivational Attribution to Buying Intention was found positive and significant. Respondents perceive that Positive Motivation towards the donor brand increases positively their Buying Intention, of the products of the donor brand.

If the company wants to improve the perception of the stakeholder through its CRM program then it should work on the fit between CRM program and company. It should emphasize that the CRM program is not a fancy affair; rather the company is seriously motivated by the increased road accidents in India and aims to reduce the rate. The company has to monitor the improvement in the rate of accidents in area where such CRM program was implemented and should do this in a continuous way. It should analyze the report and publish it for general public via print media and other social networking sites. Also such initiatives should be in a continuous way rather than in a discontinuous way. This will clear the ambiguity in the mind of people. They will be able to perceive better about the serious of the company with respect to its CRM initiatives. Then the perception about Suitability of the CRM program with the image and mission of the company will not prompt respondents to think that the CRM is a marketing gimmick to improve the image of the company, and that the company is not serious about addressing a social menace or fight for a social cause. This can improve the Evaluation of the Campaign and better the changes of Buying Intention. At present, the Buying Intention could be attributed to its quality and performance.

\section{Limitation and Direction for Future Research}

The present work looks at the process of evaluation of CRM campaign leads to positive buying intentions. The conceptual framework is tested using Structural Equation Modelling (SEM). However, like any other study, the present study too invariably bears limitations. Some of the limitations of the present study are lack of study of socio-demographic variables and their impact on the buying intentions. Future research can pay attention to these variables and test if these variables can moderate or mediate the relationships between evaluation of CRM campaign and buying intentions.

\section{Conflicts of Interest}

The authors declare no conflicts of interest regarding the publication of this paper.

\section{References}

[1] Varadarajan, P.R. and Menon, A. (1988) Cause-Related Marketing: A Coalignment of Marketing Strategy and Corporate Philanthropy. The Journal of Marketing, 52 58-74. https://doi.org/10.1177/002224298805200306

[2] Hoeffler, S. and Keller, K. (2002) Building Brand Equity through Corporate Societal Marketing. Journal of Public Policy \& Marketing, 21, 78-89. 
https://doi.org/10.1509/jppm.21.1.78.17600

[3] Nan, X. and Heo, K. (2007) Consumer Responses to Corporate Social Responsibility Initiatives: Examining the Role of Brand/Cause Fit in Cause-Related Marketing. Journal of Advertising, 36, 63-74. https://doi.org/10.2753/JOA0091-3367360204

[4] Srisuphaolarn, P. (2013) From Altruistic to Strategic CSR: How Social Value Affected CSR Development-A Case Study of Thailand. Social Responsibility Journal, 9, 56-77. https://doi.org/10.1108/17471111311307813

[5] Bowen, H. (1953) Social Responsibilities of the Businessman. Harper, New York.

[6] Davis, K. and Blomstrom, R.L. (1975) Business and Society: Environment and Responsibility. McGraw-Hill, New York.

[7] Kim, J., Song, H.J., Lee, C.K. and Lee, J.Y. (2017) The Impact of Four CSR Dimensions on a Gaming Company's Image and Customers' Revisit Intentions. International Journal of Hospitality Management, 61, 73-81. https://doi.org/10.1016/j.ijhm.2016.11.005

[8] Lacey, R., Kennett-Hensel, P.A. and Manolis, C. (2015) Is Corporate Social Responsibility a Motivator or Hygiene Factor? Insights into Its Bivalent Nature. Journal of the Academy of Marketing Science, 43, 315-332. https://doi.org/10.1007/s11747-014-0390-9

[9] Lee, J. and Lee, Y. (2015) The Interactions of CSR, Self-Congruity and Purchase Intention among Chinese Consumers. Australasian Marketing Journal, 23, 19-26. https://doi.org/10.1016/j.ausmj.2015.01.003

[10] Adkins, S. (1999) Cause Related Marketing: Who Cares Who Wins? Butterworth Heinemann, Oxford. https://doi.org/10.1016/B978-0-7506-4481-5.50010-4

[11] Tsai, S. (2009) Modeling Strategic Management for Cause-Related Marketing. Marketing Intelligence and Planning, 27, 649-665. https://doi.org/10.1108/02634500910977872

[12] Gao, Y. (2009) Corporate Social Responsibility and Consumers' Response: The Missing Linkage. Baltic Journal of Management, 4, 269-287. https://doi.org/10.1108/17465260910990984

[13] La Ferle, C., Kuber, G. and Edwards, S.M. (2013) Factors Impacting Responses to Cause-Related Marketing in India and the United States: Novelty, Altruistic Motives, and Company Origin. Journal of Business Research, 66, 364-373. https://doi.org/10.1016/j.jbusres.2011.08.017

[14] Lee, E.M., Park, S.Y., Rapert, M.I. and Newman, C.L. (2012) Does Perceived Consumer Fit Matter in Corporate Social Responsibility Issues? Journal of Business Research, 65, 1558-1564. https://doi.org/10.1016/j.jbusres.2011.02.040

[15] Bagozzi, R.P. and Yi, Y. (1988) On the Evaluation of Structural Equation Models. Journal of Academy of Marketing Science, 16, 74-94. https://doi.org/10.1007/BF02723327

[16] Amawate, V. and Deb, M. (2019) Cause Related Marketing and Customer Skepticism: A Study of Situational and Psychological Skepticism. Theoretical Economics Letters, 9, 834-851.

[17] Amawate, V. and Deb, M. (2019) Antecedents and Consequences of Consumer Skepticism toward Cause-Related Marketing: Gender as Moderator and Attitude as Mediator. Journal of Marketing Communications. https://doi.org/10.1080/13527266.2019.1630663

[18] Deb, M. (2018) Store Attributes, Relationship Investment, Culture, Religiosity and Relationship Quality: A Cross-Cultural Study. International Journal of Retail \& Dis- 
tribution Management, 46, 615-637. https://doi.org/10.1108/IJRDM-10-2017-0225

[19] Deb, M. (2014) A Study on the Factors Governing Retailer-Customer Long-Term Relationship. International Journal of Commerce and Management, 24, 257-272. https://doi.org/10.1108/IJCoMA-06-2012-0038 